\title{
Modeling leaf appearance rate for Canada Western Red Spring wheat cultivars \\ H. Wang ${ }^{1,2}$, H. Cutforth ${ }^{1}$, R. M.DePauw ${ }^{1}$, T. McCaig ${ }^{1}$, G. McLeod ${ }^{1}$, K. Brandt ${ }^{1}$, and X. Qin $^{2}$ \\ ${ }^{1}$ Semiarid Prairie Agricultural Research Centre, Agriculture and Agri-Food Canada, Box 1030, Swift Current, SK S9H 3X2, Canada (e-mail: Hong.Wang@agr.gc.ca) \\ ${ }^{2}$ Institute of Environment and Sustainable Development in Agriculture, Chinese Academy of Agricultural Sciences; Ministry of Agriculture, Key Laboratory for Agro-Environment \& Climate Change, Beijing 100081, China
}

\section{Introduction}

The rate of leaf appearance $\left(L A R\left(\right.\right.$ day $\left.\left.^{-1}\right)\right)$ is an important trait that affects seedling growth, leaf area and phasic development of wheat (Triticum aestivum L.), and hence yield. Accurately predicting $L A R$ is an important component for modeling the development and growth of wheat, and is of particular interest to farmers for the management and timing of field operations, such as herbicide application where crop tolerance to the herbicide is very dependent on leaf stage.

\section{Materials and Methods}

Two older cultivars, Marquis and Neepawa, and two new cultivars, AC Barrie and AC Elsa were grown on summerfallow on a Swinton loam soil (Orthic Brown Chernozem) near Swift Current, SK (Wang et al. 2002). From 1998 to 2001, plots measuring $11 \mathrm{~m}^{2}$ were arranged using a randomized complete block design with four replications. From each plot, 10 plants were randomly selected and marked right after seedling emergence. The main stem Haun stage was recorded for the marked plants two or three times a week. Grain yields were measured at maturity.

The following equation describes the interaction of temperature and daylength on $L A R:$

$$
L A R=\frac{\left.\operatorname{LAR}_{o 24} * \mid 1-D L F *(24-\text { Daylength })^{2}\right\rfloor}{\left\{\alpha^{\alpha} * \beta^{\beta} *\left[\left(T_{c}-T_{b}\right) /(\alpha+\beta)\right]^{(\alpha+\beta)}\right) *\left[\left(T-T_{b}\right) *\left(T_{c}-T\right)^{\beta}\right]}
$$

where $L A R o 24$ is $L A R$ at the optimum temperature when Daylength is $24 \mathrm{~h}$.

Jame et al. (1998) set $T_{\mathrm{C}}=42{ }^{\circ} \mathrm{C}$ and $T_{\mathrm{b}}=0{ }^{\circ} \mathrm{C}$ and determined the coefficients ( $L A R o 24=0.29$ day $^{-1}, D L F=0.0015, \alpha=1.5$ and $\beta=1.5$ ) through model calibration with data for Neepawa spring wheat gathered from a field study in 1990. Because of the nonlinear nature of the temperature response function, we used hourly temperature to predict $L A R$.

Simulation results were compared with observations using Pearson's correlation and the lack of fit test. Lack-of-fit tests systemic errors, which allow the experimental errors to be distinguished from the failure of the model. The statistical significance of lack of fit was obtained by comparing the $F$ value for the lack of fit [ $F$ (LOFIT)] with the $F$ critical values at the 0.05 probability level. 


\section{Results and Discussion}

For each year, the newer cultivars (AC Barrie and AC Elsa) consistently had higher grain yield than the older cultivars (Marquis and Neepawa) $(P<0.05)$ (data not shown). Over the four years, the newer cultivars averaged 19\% higher yield $\left(3.4 \mathrm{t} \mathrm{ha}^{-1}\right)$ than the older cultivars $\left(2.85 \mathrm{t} \mathrm{ha}^{-1}\right)$. The differences in the rate of main stem leaf appearance were not significant among cultivars, nor when comparing older and newer cultivars (Fig. 1). Generally, throughout the leaf growth period, AC Elsa tended to have a lower Haun stage than the other cultivars because AC Elsa consistently produced the least number of main stem leaves (Fig. 1). The mean final main stem leaf numbers averaged over the four years were 8.5 for AC Barrie, 7.7 for AC Elsa, 8.3 for Neepawa and 8.5 for Marquis. These results indicate that although grain yield was improved significantly by breeding new cultivars, LAR was not changed.

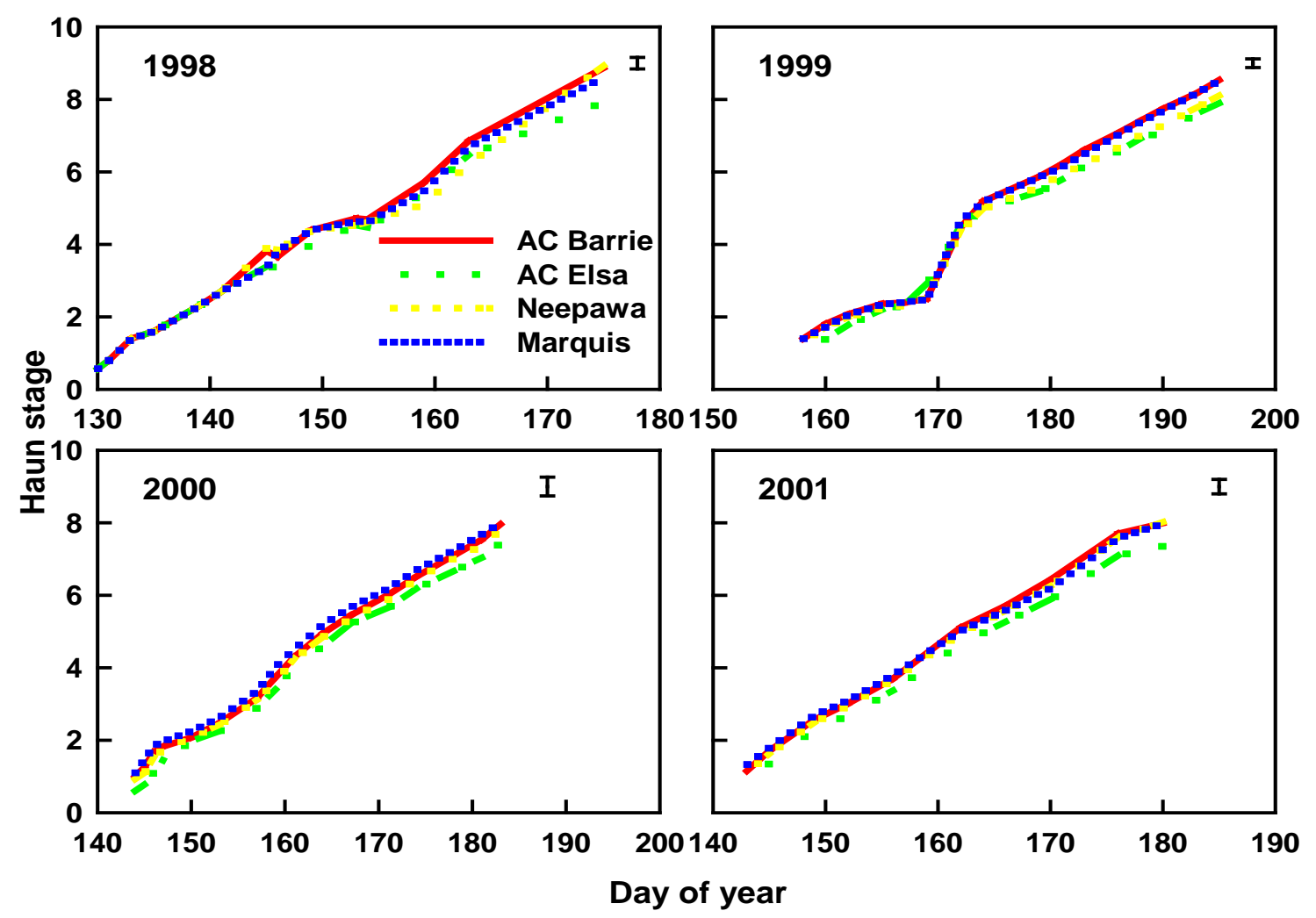

Figure 1: Main stem Haun stage observed from 1998 to 2001 near Swift Current, SK.

Vertical bars indicate LSD (0.05).

Using the LAR equation and parameters developed for Neepawa the model adequately estimated the main stem Haun stage for both Neepawa (data not shown) and the average stage for the four cultivars used in this study (Fig. 2). Every year, the simulated Haun stage was positively correlated with observed values $(P<0.001)$. Most simulated values were within the standard error of the measurements and $F$ (LOFIT) was significantly lower than the errors of measurements at $P<0.05$ (data not shown). It indicates that the model developed by Jame et al. (1998), and using the parameters determined for Neepawa, could be used to predict $L A R$ for CWRS cultivars grown in the 
semiarid prairie and it could be used as a component of growth models and decision support systems for farmers and agricultural service providers in this area.

Specific details surrounding this study will be published in the Canadian Journal of Plant Science.

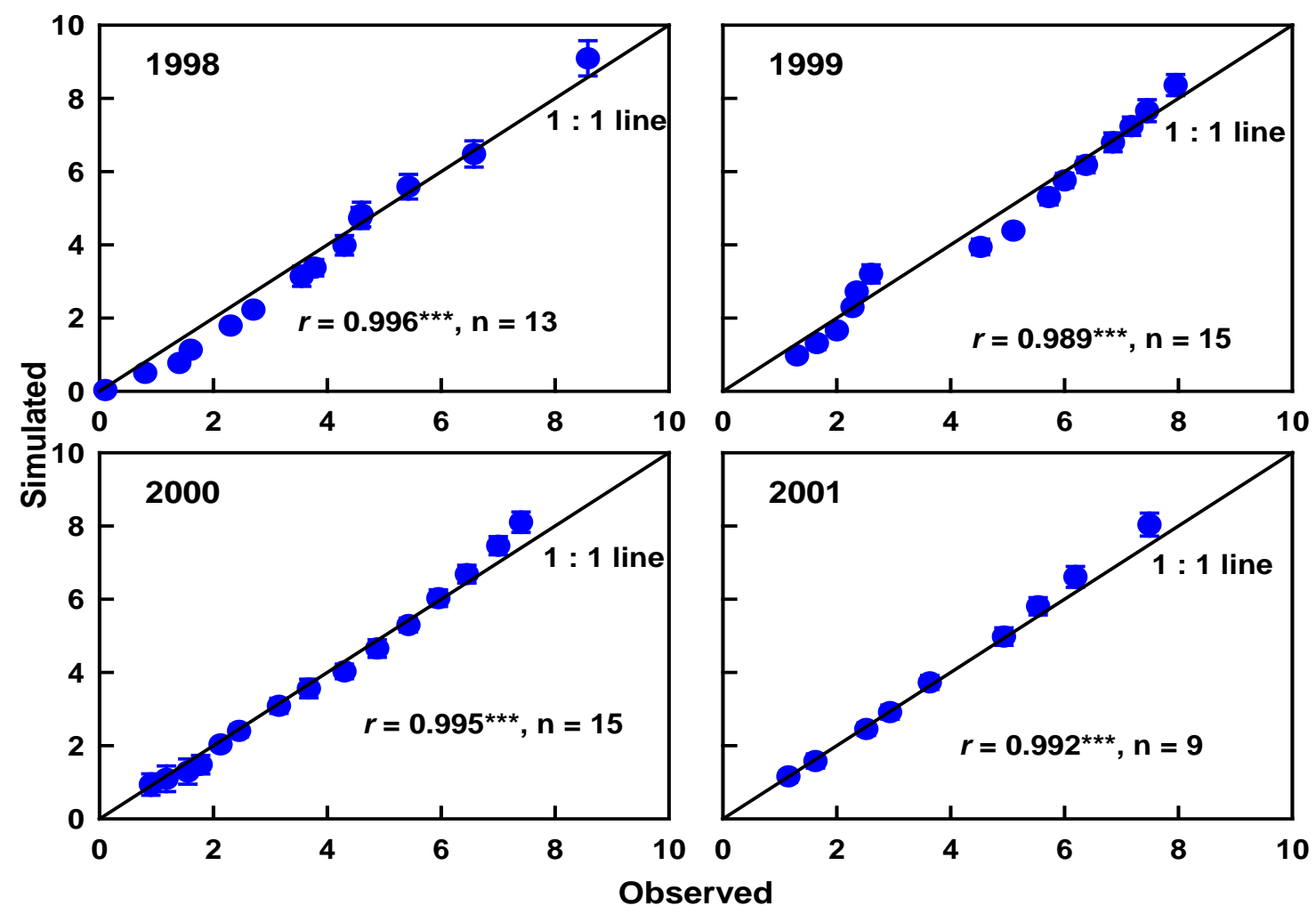

Figure 2: Observed and simulated main stem Haun stage from 1998 to 2001 near Swift Current, SK.

\section{References}

Jame, Y. W., Cutforth H. W. and Ritchie, J. T. 1998. Interaction of temperature and daylength on leaf appearance rate in wheat and barley. Agric. For. Meteorol. 92: 241249.

Wang, H., McCaig, T. N., DePauw, R. M., Clarke, F. R. and Clarke, J. M. 2002.

Physiological characteristics of recent Canada Western Red Spring wheat cultivars: Yield components and dry matter production. Can. J. Plant Sci. 82: 299-306.

Wang, H., Cutforth, H., DePauw, R. M., McCaig, T. N., McLeod, G., Brandt, K. and Qin, X. 2010. Modeling leaf appearance rate for Canada Western Red Spring wheat cultivars. Can. J. Pl. Sci. (in press). 


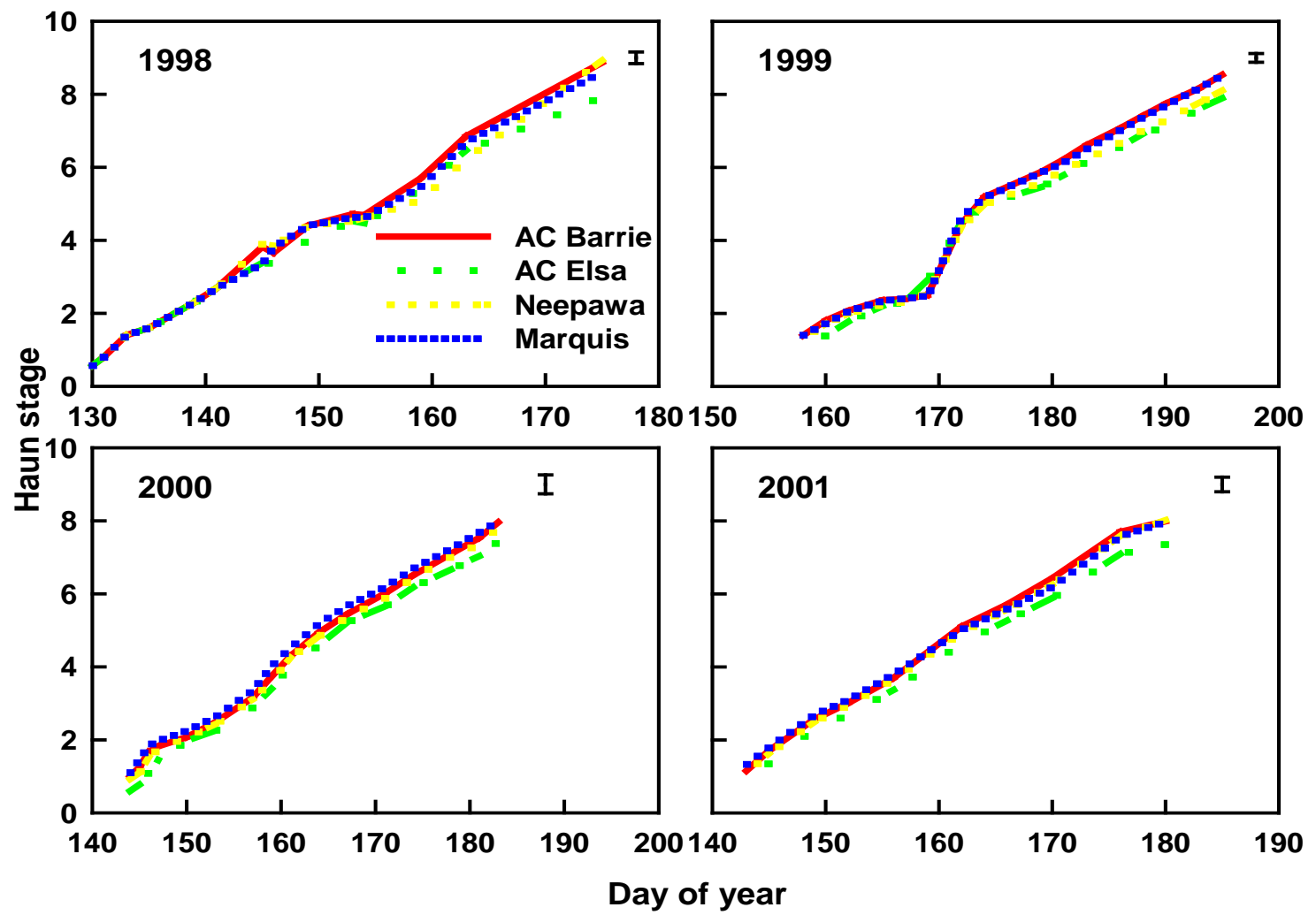

Figure 1: Main stem Haun stage observed from 1998 to 2001 near Swift Current, SK.

Vertical bars indicate LSD (0.05). 